\title{
Compressive strength and compressive fatigue limit of conventional and high viscosity posterior resin composites
}

\section{Resistência a compressão e limite de fadiga compressiva de resinas compostas convencional e de alta viscosidade para dentes posteriores}

\author{
Letícia Brandão* \\ Gelson Luis Adabo** \\ Luís Geraldo Vaz ${ }^{* * *}$ \\ José Roberto Cury Saad****
}

\begin{abstract}
The purpose of this study was to compare the compressive strengths and compressive fatigue limits of three posterior composite resins (Filtek P-60, Surefil and Prodigy Condensable) and a universal restorative composite (Z-100). Cylindrical specimens ( $8 \mathrm{~mm}$ in length $\mathrm{x} 4 \mathrm{~mm}$ in diameter) were used. The dynamic test was performed using the staircase method, and the ratio between compressive fatigue limit and compressive resistance was also calculated $(n=15)$. The compressive strength and compressive fatigue limit data were analyzed by Anova and Tukey's test. The Z-100 composite demonstrated higher compression strength (307.20 MPa) than Surefil $(266.93 \mathrm{MPa})$ and Prodigy Condensable $(222.08 \mathrm{MPa})$. The resistance of Filtek P-60 (270.44 MPa) was similar to the resistances of Z-100 and Surefil, while Prodigy Condensable presented the lowest compressive strength. In the compressive fatigue limit tests, Filtek P-60 demonstrated a higher value (184.20 MPa) than Prodigy Condensable (155.50 MPa). Surefil (165.74 MPa) and Z-100 (161.22 MPa) presented limits similar to those of Filtek P-60 and Prodigy Condensable. The compressive fatigue limit/compressive strength ratio was $70.01 \%$ for Prodigy Condensable, $68.11 \%$ for Filtek P-60, 62.09\% for Surefil and 52.48\% for Z-100. It was concluded that the Z-100 universal composite was more sensitive to the dynamic test than the high viscosity materials.
\end{abstract}

DESCRIPTORS: Composite resins; Physical properties.

\begin{abstract}
RESUMO: O objetivo deste estudo foi comparar a resistência à compressão e o limite de fadiga compressiva de três resinas compostas indicadas para dentes posteriores (Filtek P-60, Surefil e Prodigy Condensable) e uma universal (Z-100). Corpos-de-prova cilindricos ( $8 \mathrm{~mm}$ de altura x $4 \mathrm{~mm}$ de diâmetro) foram usados. O teste dinâmico foi realizado usando-se o método escada e a relação entre limite de fadiga compressiva, e resistência à compressão também foi calculada $(n=15)$. Os dados de resistência à compressão e de limite de fadiga compressiva foram submetidos à Anova e ao teste de Tukey. O compósito Z-100 apresentou maior resistência à compressão $(307,20 \mathrm{MPa})$ que Surefil $(266,93 \mathrm{MPa})$ e Prodigy Condensable $(222,08 \mathrm{MPa})$. A resistência de Filtek P-60 $(270,44 \mathrm{MPa})$ foi similar à de Z-100 e à de Surefil, enquanto Prodigy Condensable apresentou a menor resistência à compressão. No teste de limite de fadiga compressiva, Filtek P-60 mostrou maior valor (184,20 MPa) que Prodigy Condensable $(155,50 \mathrm{MPa})$. Os compósitos Surefil (165,74 MPa) e Z-100 (161,22 MPa) mostraram-se similares a Filtek P-60 e Prodigy Condensable. A relação limite de fadiga compressiva/resistência à compressão foi de 70,01\% para Prodigy Condensable, 68,11\% para Filtek P-60, 62,09\% para Surefil e 52,48\% para Z-100. Foi concluído que o compósito universal Z-100 foi mais sensivel ao teste dinâmico que os materiais de alta viscosidade.
\end{abstract}

DESCRITORES: Resinas compostas; Propriedades físicas.

\section{INTRODUCTION}

Several new materials for an esthetic restoration of posterior teeth are currently available. These materials include high density, condensable or packable resin composites. To achieve condensation, manufacturers have modified the composite resin composition using higher filler loading with

\footnotetext{
* MSc, Assistant Professor, Department of Restorative Dentistry, Federal University of Santa Maria.

** PhD, Associate Professor, Department of Dental Materials and Prosthodontics; ***PhD, Assistant Professor, Department of Dental Materials and Prosthodontics; ${ }^{* * *} \mathrm{PhD}$, Assistant Professor, Department of Restorative Dentistry - School of Dentistry of Araraquara, São Paulo State University.
} 
Brandão L, Adabo GL, Vaz LG, Saad JRC. Compressive strength and compressive fatigue limit of conventional and high viscosity posterior resin composites. Braz Oral Res 2005;19(4):272-7.

glass fibers, porous filler particles, irregular filler particles, glass filler particles and viscosity modifiers ${ }^{12}$. Because these materials are characterized by a high-filler load, they are expected to exhibit superior physical and mechanical properties ${ }^{14}$. Knobloch et al. ${ }^{11}$ (2002), while studying fracture toughness of posterior composites, observed that the most heavily filled packable material, Alert, exhibited higher fracture toughness values.

On other the hand, Moszner, Sauz ${ }^{15}$ (2001) reported that the flexural strength and modulus of these materials were slightly higher than those of conventional composites. Kelsey et al. ${ }^{9}$ (2000) studied the physical properties of three packable resin composites and remarked that Alert and Surefil were generally superior to Solitaire, but comparable to the hybrid materials (Prodigy and $Z$-100). Adabo et al. ${ }^{2}$ (2003) measured the percentage content by volume of inorganic particles and the flexural strength of esthetic restorative materials for posterior teeth, concluding that the new condensable composites present concentrations of inorganic particles similar to those of hybrid composites, but do not necessarily present higher flexural strength. Abe et al. ${ }^{1}$ (2001) verified that the elastic modulus of the packable materials Filtek P-60, Surefil, Alert, Prodigy Condensable and Solitaire II was below the elastic modulus of a conventional universal composite, Z-100.

There is great diversity in the brands of packable materials. The packable material properties vary widely and it is still not clear whether these new materials present a superior clinical performance compared to the conventional composites.

Fatigue fractures of resins after years of clinical use were found to be a common failure rea$\mathrm{son}^{13}$. Studies investigating resistance to fatigue are unable to substitute the clinical studies but may provide an estimate of the clinical performance of a material in a short period of time and incurring lower costs. Braem et al. ${ }^{6}$ (1994) reported that fatigue is a major factor in determining the life expectancy of resin composite restorations. Lohbauer et al. ${ }^{13}$ (2003), evaluating the mechanical properties of contemporary conventional and packable composites under flexural strength and flexural fatigue limits, concluded that the fatigue behavior of the materials does not correlate with initial strength values.

Since the properties of the composites for the restoration of posterior teeth are controversial while clinical and fatigue studies are scarce, the purpose of this study was to determine the compressive strength and compressive fatigue limit of four composite resins recommended for posterior teeth while also evaluating the relationship between these two properties.

\section{MATERIALS AND METHODS}

Three high viscosity (Surefil, Prodigy Condensable, Filtek P-60) and one universal conventional composite resin (Z-100) were studied (Table 1).

Cylindrical specimens, $4.0 \mathrm{~mm}$ in diameter and $8.0 \mathrm{~mm}$ long, were prepared by composite insertion into a stainless steel split mold. The materials were photocured using an XL 2500 source (3M ESPE, St. Paul, MN, USA), for 60 seconds on each extremity. The specimens were removed from the split mold and were photocured a second time for 60 seconds on each lateral face. The specimens were then stored in distilled water at $35 \pm 2{ }^{\circ} \mathrm{C}$ for 7 days.

Following storage, the compression strength test was performed in an MTS 810 mechanical test machine (MTS Systems Corporation - 14000 Technology Drive, Eden Prairie, MN, USA) at a $0.5 \mathrm{~mm} /$ min cross-head speed, determining the mean compression strength of each composite $(n=15)$.

For the compressive fatigue limit test, the mechanical test machine was programmed to operate in force mode, producing 10,000 cycles at a frequency of $5 \mathrm{~Hz}$. During fatigue testing, the specimens were immersed in distilled water. The

TABLE 1 - Name, batch number, manufacturer and type of composites.

\begin{tabular}{l|l|c}
\hline \hline \multicolumn{1}{c|}{ Material (Batch number) } & \multicolumn{1}{c}{ Manufacturer } & $\begin{array}{c}\text { Inorganic particle } \\
\text { volume }(\%)^{1}\end{array}$ \\
\hline Z-100 (8004 A 3.5 9WY) & 3M ESPE, St. Paul, MN, USA & 64.2 \\
\hline Surefil (990125) & Caulk/Dentsply, Milford, DE, USA & 60.3 \\
\hline Prodigy Condensable (905A14) & Sybron Kerr Dental Specialties, Orange, CA, USA & 52.5 \\
\hline Filtek P-60 (8100A39AW) & 3M ESPE, St. Paul, MN, USA & 62.1 \\
\hline \hline
\end{tabular}

${ }^{1}$ Information provided by the manufacturers. 
Brandão L, Adabo GL, Vaz LG, Saad JRC. Compressive strength and compressive fatigue limit of conventional and high viscosity posterior resin composites. Braz Oral Res 2005;19(4):272-7.

compressive fatigue limit was determined using the "staircase" method described by Draughn ${ }^{7}$ (1979). The initial stress was $60 \%$ of the static compression strength mean, calculated for each material. The specimens were loaded to 10,000 cycles or until specimen fracture. When the specimen resisted to 10,000 cycles, it was tested with a fixed tension increase of $4 \%$ of the initial stress. If the specimen failed before reaching 10,000 cycles, it was tested with a load reduction of $4 \%$ of the initial stress. Thus, the tension values varied (higher or lower), depending on the event of failure or non-failure.

After completing a minimum of 15 specimens tested per material, the data obtained was submitted to the statistical method proposed by Draughn ${ }^{7}$ (1979) for the determination of the compressive fatigue limit mean and standard deviation. For these calculations, the data were arranged as exemplified in Table 2. The lowest stress value was designated $i=0$, the next $i=1$, and so on. The number of failures at the given stress levels, $N=\Sigma n_{i}, B=\Sigma i^{2} n_{i}$ and $A$ is $\operatorname{\Sigma in}_{\mathrm{i}}$, was $n_{i}$.

TABLE 2 - Data for analyzing the staircase test for Surefil.

\begin{tabular}{c|c|c|c|c}
\hline \hline Stress (MPa) & $\mathrm{i}$ & $\begin{array}{c}\mathrm{n}_{\mathrm{i}} \\
\text { (Failures) }\end{array}$ & $\mathrm{in}_{\mathrm{i}}$ & $\mathrm{i}^{2} \mathrm{n}_{\mathrm{i}}$ \\
\hline 164.01 & 0 & 3 & 0 & 0 \\
\hline 174.84 & 1 & 2 & 2 & 2 \\
\hline 196.49 & 2 & 1 & 2 & 4 \\
\hline \hline
\end{tabular}

$\mathrm{N}=\Sigma \mathrm{n}_{\mathrm{i}} ; \mathrm{A}=\Sigma \mathrm{in}_{\mathrm{i}} ; \mathrm{B}=\Sigma \mathrm{i}^{2} \mathrm{n}_{\mathrm{i}}$.

TABLE 3 - Compressive Strength (MPa), standard deviation and significance.

\begin{tabular}{l|c}
\hline \hline \multicolumn{1}{c|}{ Groups } & Mean value \\
\hline $1-$ Z-100 & $307.20 \pm 12.61 \mathrm{a}$ \\
\hline $4-$ Filtek P-60 & $270.44 \pm 8.00 \mathrm{ab}$ \\
\hline 2- Surefil & $266.93 \pm 8.16 \mathrm{~b}$ \\
\hline 3 - Prodigy & $222.08 \pm 10.97 \mathrm{c}$ \\
\hline \hline
\end{tabular}

Tukey's critical value: 38.76 .
The mean compressive fatigue test was determined using Equation 1, where $\mathrm{X}_{0}$ is the lowest stress level considered in the analysis, and $d$ is the fixed stress increment (4\% initial stress).

\section{EQUATION 1:}

$\mathrm{X}=\mathrm{X}_{0}+d(\mathrm{~A} / \mathrm{N}-1 / 2)$

The standard deviation (S) is given by Equation 2, where 1.62 and 0.029 are constants.

EQUATION 2:

$\mathrm{S}=1.62 \mathrm{~d}\left(\left(\mathrm{NB}-\mathrm{A}^{2} / \mathrm{N}^{2}\right)+0.029\right)$

\section{RESULTS}

The mean values of compressive strength, and their comparison by Tukey's test, are given in Table 3. The results ranged from $307.20 \pm 12.61 \mathrm{MPa}$ for Z-100 to $222.08 \pm 10.97 \mathrm{MPa}$ for Prodigy Condensable. No statistically significant differences were detected for Z-100 and Filtek P-60. Surefil and Filtek P-60 demonstrated similar results and the Prodigy Condensable mean value was statistically different from the others.

The mean values of fatigue limit, and their comparisons by Tukey's test, are given in Table 4 . The only materials that demonstrated statistically different results were Filtek P-60 (184.20 $\pm 7.60 \mathrm{MPa})$ and Prodigy Condensable (155.50 $\pm 14.43 \mathrm{MPa})$.

The relationship between compressive strength and fatigue limit is demonstrated in Table 5. In

TABLE 4 - Mean fatigue limits ( $\mathrm{MPa})$, standard deviation and significance.

\begin{tabular}{l|c}
\hline \hline \multicolumn{1}{c|}{ Groups } & Mean \\
\hline $4-$ Filtek P-60 & $184.20 \pm 7.60 \mathrm{a}$ \\
\hline 2 - Surefil & $165.74 \pm 10.24 \mathrm{ab}$ \\
\hline $1-$ Z-100 & $161.22 \pm 5.02 \mathrm{ab}$ \\
\hline 3 - Prodigy & $155.50 \pm 14.43 \mathrm{~b}$ \\
\hline \hline
\end{tabular}

Tukey's critical value: 24.98 .

TABLE 5 - Comparison between compressive strength and fatigue limit (MPa).

\begin{tabular}{l|r|c|c}
\hline \multicolumn{1}{c|}{ Group } & Compressive Strength (CS) & Fatigue Limit (FL) & FL/CS \\
\hline $1-$ Z-100 & $307.20 \pm 12.61$ & $161.22 \pm 5.02$ & $52.48 \%$ \\
\hline 2 - Surefil & $266.93 \pm 8.16$ & $165.74 \pm 10.24$ & $62.09 \%$ \\
\hline 3 - Prodigy Condensable & $222.08 \pm 10.97$ & $155.50 \pm 14.43$ & $70.01 \%$ \\
\hline 4- Filtek P-60 & $270.44 \pm 8.00$ & $184.20 \pm 7.60$ & $68.11 \%$ \\
\hline \hline
\end{tabular}


Brandão L, Adabo GL, Vaz LG, Saad JRC. Compressive strength and compressive fatigue limit of conventional and high viscosity posterior resin composites. Braz Oral Res 2005;19(4):272-7.

all materials studied, the fatigue limit was lower than the compressive strength. The compressive fatigue limit of the materials varied from $52.48 \%$ to $70.01 \%$ of the compressive strength.

\section{DISCUSSION}

According to Reid et al. ${ }^{16}$ (1990), the progressive loss of strength in the fatigue test is due to the gradual spread of one or more cracks which accompany cyclic loads. A crack will grow by fatigue only if its opening changes cyclically. This requires a tensile force during cycling. Tensile forces are not obvious during mastication or under cyclic compression, while the cracks are apparently closing under these conditions. However, even when loading appears to be compressive, some regions of tensile stress exist, due to the decomposition of secondary stress vectors.

The use of Tukey's test to compare compressive strengths (Table 3) presented the following order of strengths: Z-100, P-60, SureFil > Prodigy Condensable.

This result may be explained by the volumetric content of the inorganic particles, as Willems et al. ${ }^{17}$ (1993) have affirmed that the filler content and size directly determine the physical and mechanical properties of composite resin materials.

Braem et al. ${ }^{5}$ (1986) proposed a direct relationship between volumetric filler concentration and elastic modulus, and suggested a mathematical model for the determination of filler content by volume from Young's dynamic modulus data. Abe et al. ${ }^{1}$ (2001) calculated the inorganic filler fraction and the dynamic elastic modulus of some composites and obtained the following values of particle concentration and modulus, respectively: Z-100 - 64.2\% and 21.0 GPa, Filtek P-60 - 62.1\% and 19.7 GPa, SureFil $-60.3 \%$ and $18.7 \mathrm{GPa}$, Prodigy Condensable $-52.5 \%$ and $14.8 \mathrm{GPa}$, presenting the same order as that found in the present study for compressive strength.

In the compressive fatigue limit test, Filtek P60 was superior to Prodigy Condensable. SureFil and Z-100 were equal to both composites.

Draughn $^{7}$ (1979) observed the fatigue limit of composite resins and compared these values to those obtained by static tests. In his study, the fatigue limit was between $63 \%$ and $73 \%$ of the compressive strength. In the present study, the fatigue limit was between $52.48 \%$ and $70.01 \%$ of the compressive strength. These observations indicate that, despite the evolution of composite materials, the fatigue limit continues to be lower than the static compressive strength.

Prodigy Condensable, Filtek P-60 and SureFill restorative materials were less sensitive to mechanical compressive cycling, showing fatigue limit/compressive strength rates of $70.01 \%, 68.11 \%$ and $62.09 \%$, respectively. Z-100 was more affected by mechanical cycling, demonstrating a compressive fatigue limit which was $52.48 \%$ lower than the compressive strength.

These data show that brittle failures cannot be explained by a lack of compressive strength, since Z-100 was the only material with a compressive strength (307.20 $\mathrm{MPa})$ comparable to that of a permanent molar teeth (305 MPa). Conversely, in the compressive fatigue test, there was no statistical significant difference between the Z-100 composite (161.22 MPa) and the Prodigy Condensable $(155.50 \mathrm{MPa})$, which presented the lowest resistance to compression in the static test.

The greater sensibility of the $Z$ - 100 composite may be related to its elevated elastic modulus.

Braem et al. ${ }^{5}$ (1986) reported that when Young's modulus of the restorative composites becomes too high, the delicate balance between brittleness, tensile strength and compressive strength is disturbed. A Young's modulus that is too high results in a brittle material that cannot withstand repetitive impact forces. Highly filled resin composites deform little under function, and the cracks move through the matrix-phase and along the filler particles. According to Htang et $a l .{ }^{8}$ (1995), the capacity of a material to resist the impact elastically is directly proportional to its resilience modulus. This value will decrease with an increase in the modulus of elasticity.

These explanations may also justify the similarity between SureFil, which has a high inorganic particle content and the greatest elasticity modulus, and Prodigy Condensable in the compressive fatigue limit test.

The fracture toughness, as well as the fatigue strength, describes the resistance of brittle materials to the catastrophic propagation of flaws. Knobloch et al. ${ }^{11}$ (2002) demonstrated that fracture toughness is a mechanical property that could help predict clinical performance. Thus, a material with a high fracture toughness will tend to resist the formation and propagation of microflaws, which may be caused by repetitive masticatory forces applied during function ${ }^{4}$.

Kelsey et al. ${ }^{9}$ (2000) demonstrated that the mean fracture toughness of SureFil (1.47 MPa. 
Brandão L, Adabo GL, Vaz LG, Saad JRC. Compressive strength and compressive fatigue limit of conventional and high viscosity posterior resin composites. Braz Oral Res 2005;19(4):272-7.

$\mathrm{m}^{0.5}$ ), Prodigy (1.22 MPa.m $\mathrm{m}^{0.5}$ ) and Z-100 (1.04 MPa. $\mathrm{m}^{0.5}$ ) were statistically different, due to their differences in modulus and filler concentration. This finding may confirm the large decrease in resistance in the fatigue test for the highest compression strength material (Z-100).

Kim et al. ${ }^{10}$ (2002) observed that the composites with the highest filler content exhibited the highest flexural strength, flexural modulus and hardness, but that the maximum fracture toughness was obtained at approximately $55 \%$ of filler volume. This was confirmed by Bonilla et $a l^{4}$ (2001), who studied linear regression analysis and showed a very weak correlation between volume particle concentration and fracture toughness. Manhart et al. ${ }^{14}$ (2000), studying the mechanical properties of various composites, obtained the same value of fracture toughness $\left(2.0 \mathrm{MN} \mathrm{m}^{3 / 2}\right)$ for SureFil and Tetric Ceram, despite the difference in their concentrations of particles per volume (60\% and $66 \%$, respectively) and flexural modulus (9.3 $\mathrm{GPa}$ and $6.8 \mathrm{GPa}$, respectively).

In addition to the type of inorganic particle content, the composition of the resin matrix is a determinant of the mechanical resistance of composites. Adabo et al. ${ }^{2}$ (2003) demonstrated that Filtek P-60 had higher flexural strength than Z100, despite the similar sizes, shapes, distributions and volumetric concentration of inorganic particles (65.27\% and $62.64 \%$, respectively). However, while the resinous phase of the $Z-100$ composite is based on the combination of Bis-GMA and TEGDMA, the Filtek P-60 had part of the solvent monomer TEDGMA replaced by UEDMA. Asmussen, Peu-

\section{REFERENCES}

1. Abe $\mathrm{Y}$, Lambrechts $\mathrm{P}$, Inoue $\mathrm{S}$, Braem MJA, Takeuchi $\mathrm{M}$, Vanherle G, et al. Dynamic elastic modulus of 'packable' composites. Dent Mater 2001;17:520-5.

2. Adabo GL, Cruz CAS, Fonseca RG, Vaz LG. The volumetric fraction of inorganic particles and the flexural strength of composites for posterior teeth. J Dent 2003;31(5):353-9.

3. Asmussen E, Peutzfeldt A. Influence of UEDMA, BisGMA and TEGDMA on selected mechanical properties of experimental resin composites. Dent Mater 1998;14(1):51-6.

4. Bonilla ED, Mardirossian G, Caputo AA. Fracture toughness of posterior resin composites. Quintessence Int 2001;32:206-10.

5. Braem M, Lambrechts P, van Doren V, Vanherle G. The impact of composite structure on its elastic response. J Dent Res 1986;65:648-53.

6. Braem M, Lambrechts P, Vanherle G. Clinical relevance of laboratory fatigue studies. J Dent 1994;22:97-102.

7. Draughn RA. Compressive fatigue limits of composite restorative materials. J Dent Res 1979;58:1093-6. tzfeldt $^{3}$ (1998) showed that varying the relative amounts of UEDMA, Bis-GMA and TEGDMA had a significant effect on the mechanical properties of the composites. This finding may explain the lower loss of resistance by Filtek P-60 in the dynamic test.

Thus, the popular supposition that the materials with a high-filler content and high compression strength have a better clinical behavior appears to be wrong. According to Lohbauer et al. ${ }^{13}$ (2003), materials providing high initial strengths do not automatically reveal the best fatigue resistance values. The development of high performance materials depends on a delicate balance between the type, size, shape and concentration of filler particles, as well as on the critical formulation of the organic phase.

\section{CONCLUSION}

Within the limits of this study, we may conclude that the Z-100 composite presented a compressive strength similar to that of Filtek P-60, while the Prodigy Condensable presented the lowest resistance to compression of all the materials tested. In the compressive fatigue limit test, there was a statistical difference between the Filtek P-60 composite and the Prodigy Condensable composite. However, the compressive fatigue limit/compressive strength ratio demonstrated that the Z-100 universal conventional composite was more sensitive to mechanical cycling than the high viscosity composites Prodigy Condensable, Filtek P-60 and Surefil.

8. Htang A, Ohsawa M, Matsumoto H. Fatigue resistance of composite restorations: Effect of filler content. Dent Mater 1995;11:7-13.

9. Kelsey WP, Latta MA, Shaddy RS, Stanislav CM. Physical properties of three packable resin-composite restorative materials. Oper Dent 2000;25:331-5.

10. Kim K-H, Ong JL, Okuno O. The effect of filler loading and morphology on the mechanical properties of contemporary composites. J Prosthet Dent 2002;87:642-9.

11. Knobloch LA, Kerby RE, Seghi R, Berlin JS, Clelland N. Fracture toughness of packable and conventional composite materials. J Prosthet Dent 2002;88(3):307-13.

12. Leevailoj C, Cochran MA, Matis BA, Moore BK, Platt JA. Microleakage of posterior packable resin composites with and without flowable liners. Oper Dent 2001;26:302-7.

13. Lohbauer U, von der Host T, Frankberger R, Krämer N, Petschelt A. Flexural fatigue behavior of resin composite restorative materials. Dent Mater 2003;19:435-40. 
Brandão L, Adabo GL, Vaz LG, Saad JRC. Compressive strength and compressive fatigue limit of conventional and high viscosity posterior resin composites. Braz Oral Res 2005;19(4):272-7.

14. Manhart J, Kunzelmann KH, Chen HY, Hickel R. Mechanical properties and wear behavior of light-cured packable composite resins. Dent Mater 2000;16:33-40.

15. Moszner N, Salz U. New developments of polymeric dental composites. Prog Colloid Polym Sci 2001;26:535-76.
16. Reid CN, Fisher J, Jacobsen PH. Fatigue and wear of dental materials. J Dent 1990;18:209-15.

17. Willems G, Lambrechts P, Braem M, Vanherle G. Composite resins in the $21^{\text {st }}$ century. Quintessence Int 1993;24:641-58.

Received for publication on Apr 14, 2005

Sent for alterations on Sep 30, 2005

Accepted for publication on Nov 07, 2005 